\title{
SARS-CoV-2 Ana Proteaz Enzimine Yönelik Antiviral Bileşiklerin Bilgisayar Destekli İlaç Tasarımı Yöntemleri ile Değerlendirilmesi
}

\author{
Gizem Tatar Y1lmaz ${ }^{1 *}$, Ercüment Y1lmaz ${ }^{2}$ \\ 1* Karadeniz Teknik Üniversitesi, Tıp Fakültesi, Biyoistatistik ve Tıp Bilişimi Anabilim Dalı, Trabzon, Türkiye, (ORCID: 0000-0001-6642-6870), \\ gizemtatar@gmail.com \\ ${ }^{2}$ Karadeniz Teknik Üniversitesi, Bilgisayar Teknolojileri Bölümü, Trabzon, Türkiye (ORCID: 0000-0002-3712-7086), ercument@ktu.edu.tr
}

(International Conference on Design, Research and Development (RDCONF) 2021 - 15-18 December 2021)

(DOI: 10.31590 /ejosat.1041077)

ATIF/REFERENCE: Tatar Yılmaz, G., Yılmaz, E., (2021). SARS-CoV-2 Ana Proteaz Enzimine Yönelik Antiviral Bileşiklerin Bilgisayar Destekli İlaç Tasarımı Yöntemleri ile Değerlendirilmesi. Avrupa Bilim ve Teknoloji Dergisi, (32), 1043-1047.

Öz

COVID-19, asemptomatik ya da hafif hastalık belirtilere sahip olup, hızlı ve şiddetli gelişen üst solunum yolları bulguları sonucunda ölüme kadar götürebilen ciddi bir hastalıktır. SARS-CoV-2'nin yeni tanımlanan bir virüs olması, kısa ve uzun dönem etkilerinin tam olarak bilinmemesi ve oluşturduğu etkilerin bireyler arasında farklılık göstermesi nedeniyle, COVID-19'un tanısı ve tedavisi güçleşmektedir. Bununla birlikte, yeni bir ilaç molekülünün keşfinde yaklaşık 5-10 bin aday molekül incelenmekte, bu aday moleküllerin arasından bir ilacın piyasaya sürülmesi 10 yıldan fazla bir zaman alabilmekte ve tüm sürecin maliyeti ise yaklaşık 330 milyon doları bulabilmektedir. İlaç keşfinin maliyetli ve zaman alan bir süreç olması göz önüne alındığında, COVID-19 pandemisine bağlı ölüm vakalarının dünya genelinde yüksek oranda seyretmesiyle birlikte bu hastalığı önleyici ve tedavi etme amaçlı ilaç ve aşı geliştirme yöntemlerinde yeni akılcı yaklaşımların önemi artmıştır. Son yıllarda bilgisayar teknolojilerindeki ilerlemelere birlikte ilaç geliştirme çalışmalarına yönelik bilgisayar destekli ilaç tasarımı (in siliko) yöntemleri geliştirilmiştir. Böylece, yüksek maliyetli ve zaman alıcı olan 1slak laboratuvar çalışmalar yerine, kısa sürede ve düşük maliyetle ilaç geliştirme süreci tamamlanabilmektedir. Bu çalışmada, bilgisayar destekli ilaç tasarım yöntemleri kullanılarak SARS-CoV-2'nin virülansında önemli rol oynayan ana proteaz $\left(\mathrm{M}^{\mathrm{pro}}\right)$ ile çeşitli viral hastalıklar için klinik olarak kullanılan 15 adet antiviral bileşiğin biyolojik aktivitelerinin araştırılması hedeflenmiştir. Çalışmanın ilk adımında SARS-CoV-2'nin ana proteaz enzimi ve antiviral bileşiklerin 3-boyutlu yapı analizleri yapılmıştır. Ardından, bilgisayar destekli ilaç tasarımı yöntemi olan moleküler kenetlenme kullanılarak her bir antiviral bileşik ile hedef enzim arasındaki bağlanma serbest enerjisi ve inhibisyon katsayısı hesaplanmıştır. Yapılan bu analiz sonucunda, Lopinavir bileşiği SARS-CoV-2 ana proteazına karşı en iyi bağlanma affinitesi gösteren bileşik olarak belirlenmiştir. Ayrıca bu bileşik, SARSCoV-2 ana proteazının aktivitesinde önemli role sahip olan Cys145, Glu166, Glu189 ve Ser144 aminoasitleri ile hidrojen bağı etkileşimi oluşturmuştur. Elde edilen sonuçlar, varolan antiviral ilaç molekülerinin biyolojik etkinliklerinin zaman ve maliyet açısından daha avantajlı sekilde irdelenmesini sağlamıştır. Bu çalışma COVID-19 tedavisine yönelik daha etkili antiviral ilaçların geliştirilmesine yönelik yapılacak klinik çalışmalara rehberlik edecektir.

Anahtar Kelimeler: COVID-19, SARS-CoV-2, SARS-CoV-2 ana proteaz, Moleküler kenetlenme, in siliko, Bilgisayar destekli ilaç tasarımı.

\section{Evaluation of Antiviral Compounds Against SARS-CoV-2 Main Protease Enzyme by Computer Aided Drug Design Methods}

\begin{abstract}
COVID-19 is a serious disease that has asymptomatic or mild disease symptoms and can lead to death as a result of rapid and severe upper respiratory tract findings. Since SARS-CoV-2 is a newly identified virus, its short and long-term effects are not fully known, and the effects it creates differ between individuals, the diagnosis and treatment of COVID-19 becomes difficult. However, in the discovery of a new drug molecule, approximately 5-10 thousand candidate molecules are examined, it may take more than 10 years to launch a drug among these candidate molecules, and the cost of the whole process can reach approximately 330 million dollars. Considering that drug discovery is a costly and time-consuming process, with the high rate of death cases due to the COVID-19
\end{abstract}

*Sorumlu Yazar: gizemtatar@gmail.com 
pandemic worldwide, the importance of new rational approaches in the development of preventive and therapeutic drugs and vaccines has increased. In recent years, computer-aided drug design (in silico) methods have been developed for drug development studies with the advances in computer technologies. Thus, instead of high-cost and time-consuming wet laboratory studies, the drug development process can be completed in a short time and at low cost. In this study, it was aimed to investigate the biological activities of the main protease $\left(\mathrm{M}^{\mathrm{pro}}\right)$, which plays an important role in the virulence of SARS-CoV-2, and 15 antiviral compounds used clinically for various viral diseases by using computer aided drug design methods. In the first step of the study, 3-dimensional structure analyzes of the main protease enzyme of SARS-CoV-2 and antiviral compounds were performed. Then, the binding free energy and inhibition constant between each antiviral compound and the target enzyme were calculated using molecular docking, which is a computer aided drug design method. As a result of this analysis, Lopinavir compound was determined as the compound with the best binding affinity against SARS-CoV-2 main protease. In addition, this compound formed a hydrogen bond interaction with Cys145, Glu166, Glu189 and Ser144 aminoacids, which have an important role in the activity of SARS-CoV-2 main protease. The results obtained provided a more advantageous examination of the biological activities of the existing antiviral drug molecules in terms of time and cost. This study will guide clinical studies to develop more effective antiviral drugs for the treatment of COVID-19.

Keywords: COVID-19, SARS-CoV-2, SARS-CoV-2 main protease, Molecular docking, in silico, Computer aided drug design.

\section{Giriş}

31 Aralık 2019'da Dünya Sağlık Örgütü (DSÖ) Çin Hastalık Kontrol ve Önleme Merkezi Wuhan şehrinde sebebi ve etiyolojisi bilinmeyen ağır pnömoni vakalarının olduğunu bildirmiştir. Ocak 2020'de bu daha önce insanlarda görülmeyen yeni bir koronavirüs tanımlanmış olup SARS-CoV'e yüksek benzerlik göstermesinden dolayı SARS-CoV-2, bu virüs sebebiyle oluşan hastalık ise COVID-19 olarak adlandırılmıştır.

Tek zincirli bir RNA virüsü olan SARS-CoV-2 dört ana yapisal protein Spike (S), Membran (M), Zarf glikoproteini (E) ve Nucleocapsid $(\mathrm{N})$ proteine ve yapisal olmayan proteinlere (nsp) sahiptir (Wu vd., 2020). Virüsun genomunda toplam 16 adet olan bu yapısal olmayan proteinler, RNA'nın replikasyon, transkripsiyon, protein sentezi ve modifikasyonu olmak üzere virüsün yaşam döngüsündeki mekanizmalarda kilit rol oynamaktadirlar.

Ana proteaz (Main protease, $\mathrm{M}^{\text {pro }}, 3 \mathrm{CLpro}$ ), virüsün yaşam döngüsünün birçok mekanizmada önemli role sahip olan bu nsp proteinlerinin olgunlaşmasında doğrudan görev aldıkları için (Jin vd., 2020), COVID-19 tedavisine yönelik yeni antiviral ilaçların geliştirilmesinde hedef enzim olmuştur. Bu doğrultuda, yapılan çeşitli ilaç geliştirme çalışmalarında, birçok farklı ilaç/ilaç adayı molekülerinin biyolojik etkinlikleri SARS-CoV-2 Mpro enzimine yönelik incelenmiştir (Amin \& Abbas, 2020; Banerjee vd., 2021; Cui vd., 2020; Kumar vd., 2020; Li vd., 2020; Zhang vd., 2020).

Günümüzde gelişen bilgisayar teknolojileri ve ilaç yazılım araçları sayesinde milyonlarca ilaç veya ilaç benzeri bileşikler birçok hastalığın oluşumda görev alan biyomolekülere karşı biyolojik etkinlikleri bilgisayar destekli ilaç tasarım yöntemleri ile araştırılmaktadır. Böylece ilaç geliştirme çalışmalarındaki maliyet, süre ve emeği minimuma indirgenerek, daha az hayvansal deneyler yapılmasına olanak sağlamaktadır.

Şu ana dek birçok hastalığın tedavisi için kullanılan ve faz aşamasında olan birçok ilaç molekülü de bilgisayar destekli ilaç tasarımı yöntemleri ile geliştirilmiştir. Özellikle virüslere karşı birçok ilaç molekülleri bu yöntemler sayesinde geliştirilerek piyasa sürülmüştür. Örnegin, İnsan Bağışıklık Yetmezlik Virüs-1 (HIV-1) inhibitörleri Saquinavir (Roberts vd., 1990), Indinavir (Rich vd., 1991), Raltegravir (Summa vd., 2008), Nelfinavir (Kaldor vd., 1997), Ritonavir (Erickson, 1993) bilgisayar destekli ilaç tasarım yöntemleri ile geliştirilmiş ilaç moleküleridir.
$\mathrm{Bu}$ bilgiler doğrultusunda, bu proje kapsamında, daha önce klinik çalışmalarda antiviral ilaç etkinliği gösteren ilaç

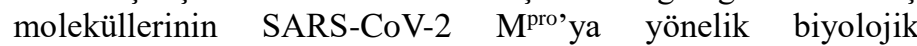
etkinliklerini ve moleküler etkileşim mekanizmalarını in siliko yöntemler ile analiz edilerek COVID-19 tedavisine yönelik en hızlı şekilde ilaç tedavi yöntemlerinin geliştirmesi hedeflenmiştir.

\section{Materyal ve Metot}

\subsection{Enzim ve Antiviral İlaç Molekülerinin 3-Boyutlu (3B) Yapılarının Hazırlanması}

SARS-CoV-2 Mpro enziminin 3-boyutlu (3B) kristal yap1 için, N3 inhibitörü içeren 2.16 Á çözünürlüğüne sahip 6LU7 pdb kodlu yap1, protein veri bankasından seçilmiştir. Protein veri tabanı vasitasıyla elde edilen bu kristal yapıdan su ve iyon molekülleri uzaklaşılarak eksik hidrojen atomları ve atomlara ait yükler $\mathrm{pH}=7$ ortamında APBS-PDB2PQR programı (Jurrus vd., 2018) ile eklenmiştir. Aynı zamanda, antiviral bileşiklerin 3B yapıları ise PubChem (Kim vd., 2019) veritabandan .sdf dosya forma ile bilgisayar ortamına yüklenmiştir. $\mathrm{Bu}$ moleküler, Discovery studio Client programı (Dassault Systèmes BIOVIA. Discovery Studio Modeling Environment, Release 2020. San Diego) vasitasıyla .sdf dosya formatından .pdb dosya formatına çevrilmiştir. Belirtilen doğrultuda, enzim ve antiviral bileşikler gerekli hazırlık işlemleri tamamlanmış olup moleküler kenetlenme analizine geçilmiştir.

\subsubsection{Moleküler Kenetlenme Analizi}

Hedef olarak belirlenen SARS-CoV-2 $\mathrm{M}^{\text {pro }}$ proteininin 3boyutlu yapısı ile piyasada mevcut antiviral bileşiklerin biyolojik etkinlik tahminini ve etki mekanizmasını aydınlatabilmek için yapı temelli (hedef yapı tabanlı) bilgisayar destekli ilaç tasarım yöntemi olan moleküler kenetlenme analizi uygulanmıştır.

Moleküler kenetlenme (docking) yöntemleri için geliştirilmiş çeşitli uygulamalar bulunmaktadır. Çalışmamızda, bu uygulamalardan biri olan AutoDock 4.2 (Morris vd., 2009) ile moleküler kenetleme analizleri gerçekleştirilmiştir. $\mathrm{Bu}$ uygulamada, ligand yapılarının esnek olarak hedef enzimin bağlanma bölgesine en kararlı şekilde bağlanmasını sağlamak için genetik algorithmalardan yararlanılmaktadır. Bu doğrultuda, bu analiz için ligand molekülün hedef enziminin bağlanma bölgesine optimum konformasyon taraması amaciyla hibrit bir genetik algoritma olan Lamarckian Genetik Algoritması (LGA) kullanilarak $N_{\text {score-evals }}^{M A X}=2.500 .000, N_{\text {gens }}^{M A X}=27.000$ standart parametrelerle 100 çalıştırma adımı (koşum) uygulanmıştır. 
$\mathrm{Bu}$ algorithmada, çözüm için üretilecek popülasyonlar çaprazlama, mutasyon, seçim vb. oprasyonlar ile elde edilmektedir. $\mathrm{Bu}$ işlemlerin hemen ardından da lokal arama (LA) işlemi gerçekleştirilmektedir. Lokal arama işleminde popülasyonun bir alt kümesinde lokal optimizasyon uygulanmaktadır. Her çözüm bir genotip olarak kodlanmakta ve Ngenes olarak ifade edilmektedir. LGA koşum süresi, mevcut puan değerlendirmeleri ve evrim adedi tarafindan belirlenir. (Solis-Vasquez vd., 2020). LGA algoritmasının çalıştırması süreci varsayılan olarak $N_{\text {score-evals }}^{M A X}=2.500 .000 \quad$ veya $N_{\text {gens }}^{M A X}=27.000$ sinırlarından birine ulaştığında sona erer. $\mathrm{Bu}$ algoritmanın çalışma prensibi olan algoritma Şekil 1'de verilmiştir.

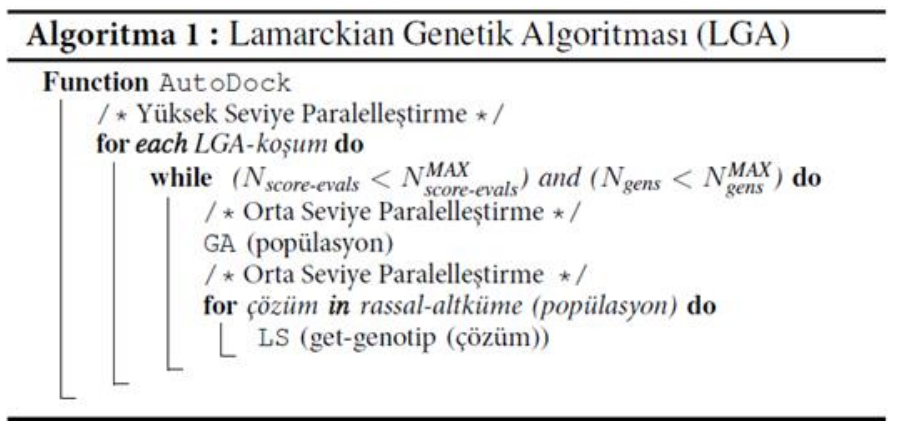

Şekil 1. Lamarckian Genetik Algoritması (LGA)

$\mathrm{Bu}$ LGA algoritmasın çalışma prensibi sonucunda ligandın farklı pozları üretilir. Üretilen herbir ligand pozu ile enzim arasındaki etkileşim enerjilerinin hesaplaması için skorlama fonksiyonlarından faydalanır (Şekil 2).

$\mathrm{Bu}$ skorlama fonsksiyonunda belirtilen her bir ligand pozu ile enzim yapısı için enzim ve ligand molekülün bağsız durumlarındaki intramoleküler, ligand ve enzimin birbiriyle bağlı durumdaki intermoleküler enerjileri ve bağlanma sirasındaki konformasyonel entrolpinin $(\Delta S)$ iteratif olarak hesaplanarak toplam serbest enerji $(\Delta G)$ Denklem (1)'e göre bulunmaktadir.

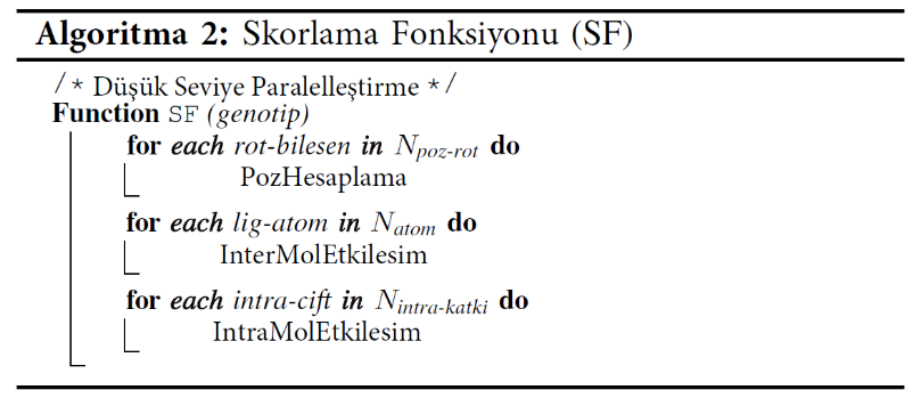

Şekil 2. Skorlama Fonksiyonu (SF)

$$
\begin{aligned}
\Delta G= & \left(V_{b a \mathrm{ğll}}^{L-L}-V_{b a \mathrm{ğ} s l z}^{L-L}\right)+\left(V_{b a \mathrm{ğ} l l}^{P-P}-V_{b a \mathrm{ğ} s l z}^{P-P}\right) \\
& +\left(V_{\text {bağ } l l}^{P-L}-V_{\text {bağslz }}^{P-L}+\Delta S_{\text {konf }}\right)
\end{aligned}
$$

Denklem (1)'de, V notasyonu ile ifade edilen enerjiler, sırasıyla Denklem (2)'de verilen, Lennard-Jones, Hidrojen bağ, elektrostatik, çözünürlük değer tahminlerinden oluşur.

$$
\begin{gathered}
V=W_{v d w} \sum_{i, j}\left(\frac{A_{i j}}{r_{i j}^{12}}-\frac{B_{i j}}{r_{i j}^{6}}\right)+W_{h b a \mathrm{ğ} l} \sum_{i, j} E(t)\left(\frac{C_{i j}}{r_{i j}^{12}}-\frac{D_{i j}}{r_{i j}^{10}}\right) \\
+W_{\text {elec }} \sum_{i, j} \frac{q_{i} q_{j}}{\varepsilon\left(r_{i j}\right) r_{i j}}+W_{s o l} \sum_{i, j}\left(S_{i} V_{j}+S_{j} V_{i}\right) e^{\left(-r_{i j}^{2} / 2 \sigma^{2}\right)}
\end{gathered}
$$

\section{Araştırma Sonuçları ve Tartışma}

\subsection{Moleküler Kenetlenme Sonuçları}

Moleküler docking analizlerine göre, SARS-CoV-2 $\mathrm{M}^{\text {pro }}$ enziminin kristal yapısında mevcut olan N3 inhibitörü (referans inhibitör) için bağlanma serbest enerjisi $-8.31 \mathrm{kcal} / \mathrm{mol}$ olarak hesaplanmıştır. Diğer 15 adet antiviral bileşikler ise N3 inhibitörüne göre negatif yönde yüksek bağlanma serbest enerji değerine sahip olarak bu referans bileşiğe göre hedef enzime daha iyi bağlanma affinitesi (ilgisi) göstermiştir. Bu bileşikler arasından ise Lopinavir bileşiği $-10.85 \mathrm{kcal} / \mathrm{mol}$ bağlanma enerjisi ile SARS-CoV-2 $\mathbf{M}^{\text {pro }}$ enzimine en iyi bağlanma affinitesi gösteren antiviral bileşiktir (Tablo 1).

Tablo 1. Moleküler docking analizi sonucunda herbir bileşik ile SARS-CoV-2 Mro enziminin bağlanma enerjisi değerleri

\begin{tabular}{l|c}
\hline Kimyasal bileşik adı & Bağlanma Enerjisi (kcal/mol) \\
\hline Reference İnhibitor (N3) & -8.31 \\
\hline Lopinavir & -10.85 \\
\hline Ritonavir & -8.43 \\
\hline Darunavir & -10.02 \\
\hline Nafamostat & -9.51 \\
\hline Loperamide & -9.02 \\
\hline Umifenovir & -8.36 \\
\hline Imatinib mesylate & -10.35 \\
\hline Dasatinib & -8.73 \\
\hline Selumetinib & -8.57 \\
\hline Trametinib & -9.27 \\
\hline Rapamycin & -8.31 \\
\hline Saracatinib & -9.47 \\
\hline Fluphenazine & -8.57 \\
\hline Thiethylperazine & -8.88 \\
\hline Camostat & -8.42 \\
\hline
\end{tabular}

Kristal yapıdaki referans bileşik N3, His41 ile pi-sigma, Met165 ile pi-sülfür, Leu141 ile alkil, His163 ve His164 ile pialkil, Glu166, Arg188, Thr190, Gln189 ile hidrojen bağ etkileşimleri meydana getirmiştir (Şekil 3). 

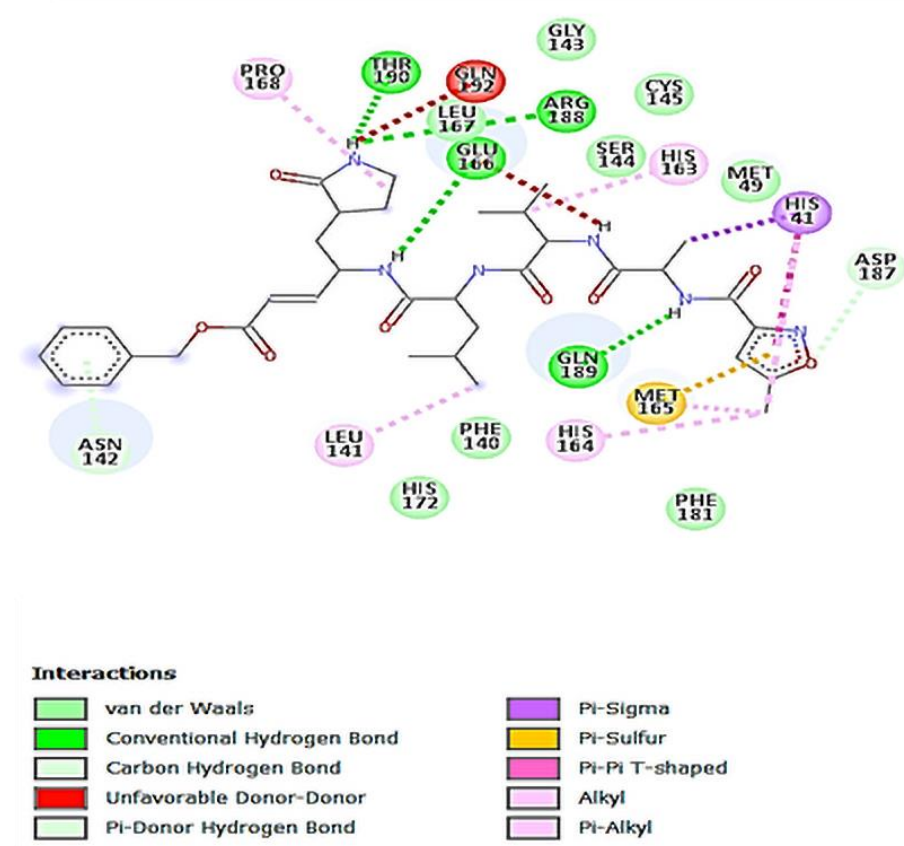

Şekil 3. Moleküler docking analizi sonucunda SARS-CoV-2 Mro enzimi ile N3 inhibitörü (referans inhibitör) ile etkileşim bölgesinin 2-boyutlu gösterimi

Bağlanma ilgisi en yüksek olan Lopinavir bileşiği ise Mpro enziminin bağlanma bölgesinde enzim aktivitesinde önemli role sahip olan Glu166, Gln189, Leu141, Ser144 ve Cys145 aminoasitleri ile hidrojen bağ etkileşimi, Cys44 ve Met 49 ile pisülfür, His163, Pro168 ve Met 165 ile pi-alkil bağ etkileşimleri oluşturmuştur (Şekil 4).

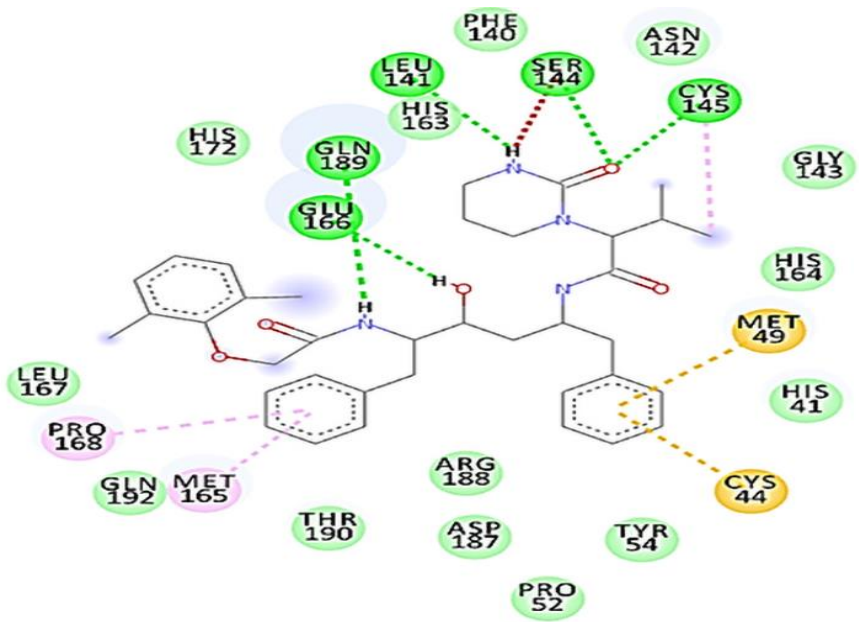

Interactions
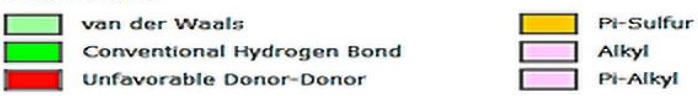

Şekil 4. Moleküler docking analizi sonucunda SARS-CoV-2 Mpro enzimi ile Lopinavir bileşiği ile etkileşim bölgesinin 2-boyutlu gösterimi

\section{Sonuç}

Yapılan bu çalışma sonucunda, klinik çalışmalarda kullanılan 15 adet antiviral bileşiğin COVID-19 ilaç tedavisine

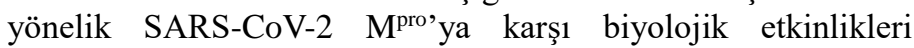
bilgisayar destekli ilaç tasarım yöntemleri ile incelenmiştir. Bu analiz sonuçlarına göre, incelenen 15 adet bileşik enzim yapısına ait referans bileşiğe göre daha iyi biyolojik etkinlik göstermiş olup, hedef enzimin katalitik aktivitesinde önemli role sahip aminoasitlerle uzak bağ etkileşimeleri sergilemişlerdir. $\mathrm{Bu}$ bilgiler doğrultusunda, ilerleyen aşamalarda incelenen bu inhibitör yapılarının moleküler docking yöntemi ile tahmin edilen pozunun kararlı olup olmadığını ve protein yapısında bir konformasyon değişimleri incelemek için moleküler dinamik simülasyon çalışmalarının yapılması planlanmaktadır.

Elde edilen bu veriler sonucunda, COVID-19 tedavisine yönelik daha etkin yeni antiviral ilaçların daha hızlı, isabetli ve güvenilir sekilde klinik çalışmalarının yapılmasına olanak sağlanacaktır. Ayrıca bu çalısma, bu virüs ile aynı aileye sahip ve genomik olarak oldukça benzerlik gösteren diger insan koronavirüslerin SARS-CoV, MERS-CoV gibi yol açtıgı enfeksiyon ile mücadeledeki ilaç geliştirme çalısmaları içinde önemli bilimsel katkılar sunacaktır.

\section{Teşekkür}

$\mathrm{Bu}$ çalışmada, moleküler docking yöntemine ait hesaplamalar için TRUBA kaynaklarının kullanılmasına olanak sağlayan TÜBİTAK ULAKBİM'e teşekkür ederiz.

\section{Kaynakça}

Amin, M., \& Abbas, G. (2020). Docking study of chloroquine and hydroxychloroquine interaction with RNA binding domain of nucleocapsid phospho-protein - an in silico insight into the comparative efficacy of repurposing antiviral drugs. Journal of Biomolecular Structure and Dynamics, $1-13$.

Banerjee, R., Perera, L., \& Tillekeratne, L. M. V. (2021). Potential SARS-CoV-2 main protease inhibitors. Drug Discovery Today, 26(3), 804-816.

Cui, W., Yang, K., \& Yang, H. (2020). Recent Progress in the Drug Development Targeting SARS-CoV-2 Main Protease as Treatment for COVID-19. Frontiers in Molecular Biosciences, 7.

Dassault Systèmes BIOVIA. Discovery Studio Modeling Environment, Release 2020. San Diego: Dassault Systèmes; 2020.

Erickson, J. W. (1993). Design and structure of symmetry-based inhibitors of HIV-1 protease. Perspectives in Drug Discovery and Design, 1(1), 109-128.

Jin, Z., Du, X., Xu, Y., Deng, Y., Liu, M., Zhao, Y., Zhang, B., Li, X., Zhang, L., Peng, C., Duan, Y., Yu, J., Wang, L., Yang, K., Liu, F., Jiang, R., Yang, X., You, T., Liu, X., ... Yang, H. (2020). Structure of Mpro from SARS-CoV-2 and discovery of its inhibitors. Nature, 582(7811), 289-293.

Jurrus, E., Engel, D., Star, K., Monson, K., Brandi, J., Felberg, L. E., Brookes, D. H., Wilson, L., Chen, J., Liles, K., Chun, M., Li, P., Gohara, D. W., Dolinsky, T., Konecny, R., Koes, D. R., Nielsen, J. E., Head-Gordon, T., Geng, W., ... Baker, N. A. (2018). Improvements to the APBS biomolecular solvation software suite. Protein Science, 27(1), 112-128.

Kaldor, S. W., Kalish, V. J., Davies, J. F., Shetty, B. V., Fritz, J. E., Appelt, K., Burgess, J. A., Campanale, K. M., Chirgadze, N. Y., Clawson, D. K., Dressman, B. A., Hatch, S. D., Khalil, D. A., Kosa, M. B., Lubbehusen, P. P., Muesing, M. A., Patick, A. K., Reich, S. H., Su, K. S., \& Tatlock, J. H. 
(1997). Viracept (nelfinavir mesylate, AG1343): A potent, orally bioavailable inhibitor of HIV-1 protease. Journal of Medicinal Chemistry, 40(24), 3979-3985.

Kim, S., Chen, J., Cheng, T., Gindulyte, A., He, J., He, S., Li, Q., Shoemaker, B. A., Thiessen, P. A., Yu, B., Zaslavsky, L., Zhang, J., \& Bolton, E. E. (2019). PubChem 2019 update: Improved access to chemical data. Nucleic Acids Research, 47(D1), D1102-D1109.

Kumar, D., Kumari, K., Vishvakarma, V. K., Jayaraj, A., Kumar, D., Ramappa, V. K., Patel, R., Kumar, V., Dass, S. K., Chandra, R., \& Singh, P. (2020). Promising inhibitors of main protease of novel corona virus to prevent the spread of COVID-19 using docking and molecular dynamics simulation. Journal of Biomolecular Structure and Dynamics, 1-15.

Li, Z., Li, X., Huang, Y.-Y., Wu, Y., Liu, R., Zhou, L., Lin, Y., Wu, D., Zhang, L., Liu, H., Xu, X., Yu, K., Zhang, Y., Cui, J., Zhan, C.-G., Wang, X., \& Luo, H.-B. (2020). Identify potent SARS-CoV-2 main protease inhibitors via accelerated free energy perturbation-based virtual screening of existing drugs. Proceedings of the National Academy of Sciences, 117(44), 27381-27387.

Morris, G. M., Huey, R., Lindstrom, W., Sanner, M. F., Belew, R. K., Goodsell, D. S., \& Olson, A. J. (2009). AutoDock4 and AutoDockTools4: Automated Docking with Selective Receptor Flexibility. Journal of computational chemistry, 30(16), 2785-2791.

Rich, D. H., Sun, C. Q., Prasad, J. V. N. V., Pathiasseril, A., Toth, M. V., Marshall, G. R., Clare, M., Mueller, R. A., \& Houseman, K. (1991). Effect of hydroxyl group configuration in hydroxyethylamine dipeptide isosteres on HIV protease inhibition. Evidence for multiple binding modes. Journal of Medicinal Chemistry, 34(3), 1222-1225.

Roberts, N. A., Martin, J. A., Kinchington, D., Broadhurst, A. V., Craig, J. C., Duncan, I. B., Galpin, S. A., Handa, B. K., Kay, J., \& Kröhn, A. (1990). Rational design of peptide-based HIV proteinase inhibitors. Science (New York, N.Y.), 248(4953), 358-361.

Solis-Vasquez, L., Santos-Martins, D., Koch, A., \& Forli, S. (2020). Evaluating the Energy Efficiency of OpenCLaccelerated AutoDock Molecular Docking. 2020 28th Euromicro International Conference on Parallel, Distributed and Network-Based Processing (PDP), 162-166.

Summa, V., Petrocchi, A., Bonelli, F., Crescenzi, B., Donghi, M., Ferrara, M., Fiore, F., Gardelli, C., Gonzalez Paz, O., Hazuda, D. J., Jones, P., Kinzel, O., Laufer, R., Monteagudo, E., Muraglia, E., Nizi, E., Orvieto, F., Pace, P., Pescatore, G., ... Rowley, M. (2008). Discovery of Raltegravir, a Potent, Selective Orally Bioavailable HIV-Integrase Inhibitor for the Treatment of HIV-AIDS Infection. Journal of Medicinal Chemistry, 51(18), 5843-5855.

Wu, A., Peng, Y., Huang, B., Ding, X., Wang, X., Niu, P., Meng, J., Zhu, Z., Zhang, Z., Wang, J., Sheng, J., Quan, L., Xia, Z., Tan, W., Cheng, G., \& Jiang, T. (2020). Genome Composition and Divergence of the Novel Coronavirus (2019-nCoV) Originating in China. Cell Host \& Microbe, 27(3), 325-328.
Zhang, L., Lin, D., Sun, X., Curth, U., Drosten, C., Sauerhering, L., Becker, S., Rox, K., \& Hilgenfeld, R. (2020). Crystal structure of SARS-CoV-2 main protease provides a basis for design of improved $\alpha$-ketoamide inhibitors. Science, 368(6489), 409-412. 